\title{
Pneumomediastinum complicating granulomatous- lymphocytic interstitial lung disease in common variable immunodeficiency
}

\author{
Konstantinos Stefanidis (1) , 'Vasileios Rafailidis, ${ }^{1}$ Ioasaf Karafotias, ${ }^{2}$ Sa Tran ${ }^{1}$
}

'Department of Radiology, King's College Hospital NHS Foundation Trust, London, UK ${ }^{2}$ Department of Allergy and Immunology, King's College Hospital NHS Foundation Trust, London, UK

\section{Correspondence to}

Dr Konstantinos Stefanidis; kstefanidis@nhs.net

Accepted 12 June 2020

\section{DESCRIPTION}

A 41-year-old male Caucasian patient presented with dyspnoea, with a background of bronchiectasis secondary to common variable immunodeficiency (CVID). Initial investigation included a pulmonary function test showing a restrictive defect and a CT of the chest for the investigation of possible granulomatous disease. The CT showed interstitial fibrosis with patchy areas of subpleural and peribronchovascular consolidation (figure 1A), consistent with granulomatous-lymphocytic interstitial lung disease (GLILD), proven on transbronchial biopsy. The scan also revealed a small spontaneous pneumomediastinum (figure $1 \mathrm{~B}, \mathrm{C}$ ) most likely as a complication of recurrent infections and coughing treated conservatively as it responds well to conservative treatment. On the mediastinal window settings, there were multiple enlarged and prominent mediastinal and hilar lymph nodes (figure 2A). To exclude an underlying lymphoproliferative disease, endobronchial ultrasound-guided transbronchial needle aspiration was performed, showing non-necrotising granulomatous inflammation.

CVID is the most common clinically significant primary immunodeficiency in the adult, associated with high risk for recurrent infections: lymphoproliferative, granulomatous and autoimmune diseases. CVID patients may develop a combination of granulomatous and lymphoproliferative lung disease known as GLILD. This is a lung complication of CVID indicating worse prognosis. ${ }^{1}$ The incidence of GLILD in CVID is approximately 25\% with a

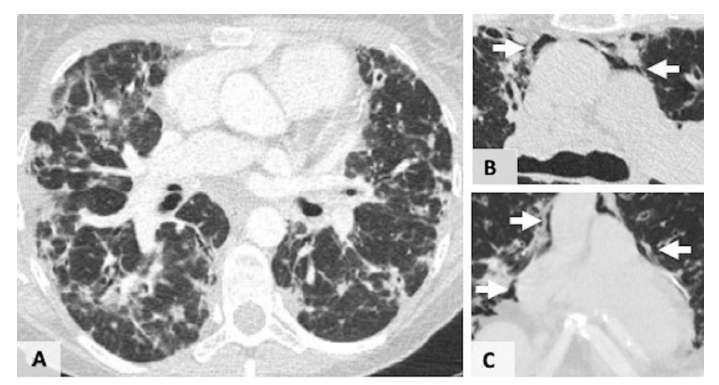

Figure 1 (A) Axial CT image of the chest in a patient with common variable immunodeficiency, showing interstitial fibrosis with subpleural and peribronchovascular consolidation consistent with granulomatous-lymphocytic interstitial lung disease, proven on lung biopsy. $(\mathrm{B}, \mathrm{C})$ Axial $\mathrm{CT}$ image and coronal reconstruction showing the small spontaneous pneumomediastinum (arrows) as a complication of recurrent infections and coughing in the same patient.

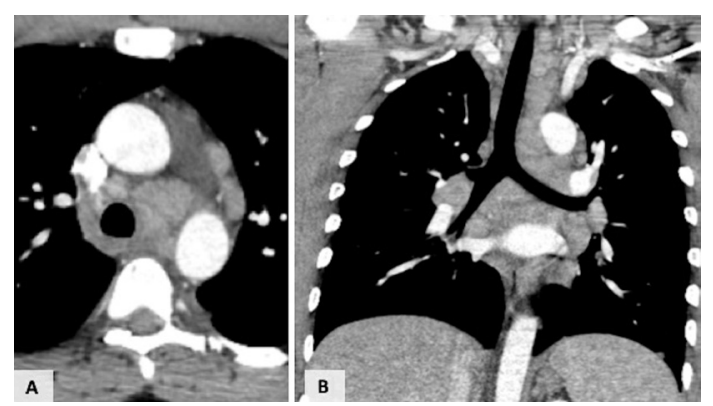

Figure $2(A, B)$ Axial and coronal $C T$ images showing mediastinal and hilar lymphadenopathy in the same patient with granulomatous common variable immunodeficiency. Endobronchial ultrasound histology showed non-necrotising granulomatous inflammation.

higher prevalence in the late adolescent to young adult age range. ${ }^{1}$ The pathological changes are complex and overlapping, including follicular bronchiolitis, lymphoid hyperplasia, lymphocytic interstitial pneumonia and sarcoid-like granulomatous reactions. ${ }^{12}$ The pathological changes reflect the radiological appearances on CT. Typical radiological findings of GLILD on CT include micronodules, ground-glass opacities, bronchiectasis, patchy consolidations and a diffuse reticular pattern with a lower zone predominance. ${ }^{3} 4$ The imaging and clinical pattern is often difficult to distinguish from pulmonary sarcoidosis especially in cases with increased ACE levels. ${ }^{5}$ However, the lower zone predominance of the abnormalities and the

\section{Learning points}

Granulomatous-lymphocytic interstitial lung disease (GLILD) represents one of the most important complications of common variable immunodeficiency with a combination of overlapping histological and radiological patterns of lymphocytic interstitial pneumonia, follicular bronchiolitis, granulomatous lung disease and organising pneumonia.

- A diagnosis of GLILD indicates worse prognosis with an increased risk of a lymphoproliferative disease complication.

- Screening examinations, such as pulmonary function testing and CT of the chest, can be used to evaluate pulmonary status and detect possible complications such as pneumomediastinum. 
presence of bronchiectasis appear to distinguish GLILD from sarcoidosis. ${ }^{3}$ Intrathoracic lymphadenopathy and splenomegaly are also common findings, mimicking lymphoma, which should be considered and excluded, given the significantly higher prevalence of lymphoma in this group of CVID patients compared with general population. ${ }^{6}$ To the best of our knowledge, complications as pneumomediastinum and pneumothorax in the context of GLILD are not previously described in the literature; however, it is considered a known complication in the background of ILD.

Contributors ST and KS: identified the case and did conception and design. KS and VR: literature search. KS, IK and VR: drafting the manuscript. KS, IK, VR and ST: revising the manuscript critically for important intellectual content and final approval of the version to be published.

Funding The authors have not declared a specific grant for this research from any funding agency in the public, commercial or not-for-profit sectors.

Competing interests None declared.

Patient consent for publication Obtained.
Provenance and peer review Not commissioned; externally peer reviewed.

\section{ORCID iD}

Konstantinos Stefanidis http://orcid.org/0000-0001-6127-1523

\section{REFERENCES}

1 Bates CA, Ellison MC, Lynch DA, et al. Granulomatous-lymphocytic lung disease shortens survival in common variable immunodeficiency. J Allergy Clin Immunol 2004:114:415-21.

2 Rao N, Mackinnon AC, Routes JM. Granulomatous and lymphocytic interstitial lung disease: a spectrum of pulmonary histopathologic lesions in common variable immunodeficiency--histologic and immunohistochemical analyses of 16 cases. Hum Pathol 2015:46:1306-14.

3 Park JES, Beal I, Dilworth JP, et al. The HRCT appearances of granulomatous pulmonary disease in common variable immune deficiency. Eur I Radiol 2005;54:359-64.

4 Torigian DA, LaRosa DF, Levinson Al, et al. Granulomatous-lymphocytic interstitial lung disease associated with common variable immunodeficiency: CT findings. I Thorac Imaging 2008;23:162-9.

5 Verbsky JW, Routes JM. Sarcoidosis and common variable immunodeficiency: similarities and differences. Semin Respir Crit Care Med 2014:35:330-5.

6 Chua I, Quinti I, Grimbacher B. Lymphoma in common variable immunodeficiency: interplay between immune dysregulation, infection and genetics. Curr Opin Hematol 2008;15:368-74.

Copyright 2020 BMJ Publishing Group. All rights reserved. For permission to reuse any of this content visit

https://www.bmj.com/company/products-services/rights-and-licensing/permissions/

BMJ Case Report Fellows may re-use this article for personal use and teaching without any further permission.

Become a Fellow of BMJ Case Reports today and you can:

- Submit as many cases as you like

- Enjoy fast sympathetic peer review and rapid publication of accepted articles

- Access all the published articles

Re-use any of the published material for personal use and teaching without further permission

\section{Customer Service}

If you have any further queries about your subscription, please contact our customer services team on +44 (0) 2071111105 or via email at support@bmj.com.

Visit casereports.bmj.com for more articles like this and to become a Fellow 